\title{
Modeling of a falling film evaporator
}

\author{
Alberto de la Calle ${ }^{a} \quad$ Luis J. Yebra $^{a} \quad$ Sebastián Dormido $^{b}$ \\ ${ }^{a}$ CIEMAT-Plataforma Solar de Almería, Ctra. de Senés s/n, 04200 Tabernas, Spain \\ ${ }^{b}$ UNED, Escuela Técnica Superior de Ingeniería Informática, 28040 Madrid, Spain
}

\begin{abstract}
Falling film evaporators have demonstrated a good performance in air-conditioning and refrigeration. This paper presents the development of a detailed falling film evaporator model. The model is based on classical Newton's viscosity law and Nusselt falling film theory. A library of evaporator components compatible with Modelica.Fluid, Modelica.Thermal and Modelica.Media has been implemented. The simulations presented have the expected behaviour. These models will be used to a complete model of a heat pump.
\end{abstract}

Keywords: Falling film; evaporator; heat pump; dryout; object-oriented modeling;

\section{Introduction}

One of the difficulties of working with solar energy is its variability. Since this technology starts, researchers have studied how to avoid solar irradiance disturbances affect energy production. The proposed solutions range from thermal storage to auxiliary energy sources to make feasible facilities.

With the aim of testing and developing a solar thermal Multi-Effect Distillation (MED), AQUASOL experimental thermal desalination plant was built at CIEMAT-Plataforma Solar de Almería at the early nineties [6]. Presently, the experimental plant performs an hybrid solar-gas process that combines, a thermal desalination system and a solar field with a Double Effect Absorption Heat Pump (DEAHP) coupled with a gas boiler [3] ( Fig. 1). This system achieves at the same time the design requirements of low-cost, high efficiency and zero discharge [1].

The MED plant is a 14-effect plant where the seawater descends due to gravity from the $1^{\text {st }}$ to $14^{\text {th }}$ effects achieving a $3 \mathrm{~m}^{3} / \mathrm{h}$ nominal distillate production ( Fig. 1). In the effect 1 , the seawater is preheated by hot water $\left(66.5^{\circ} \mathrm{C}\right)$ coming from a $12-\mathrm{m}^{3}$ primary storage tank. Energy supplied to the primary tank can be trans-



Figure 1: AQUASOL project plant flow sheet

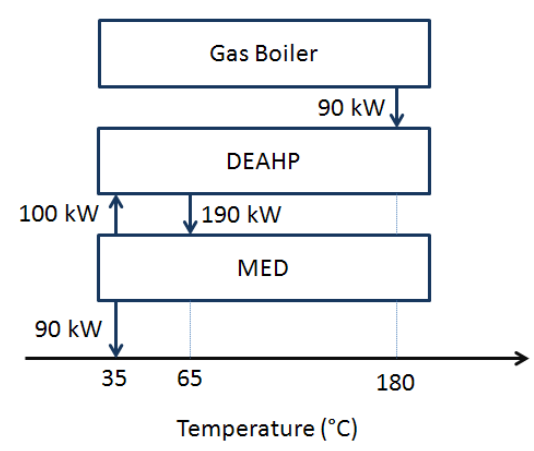

Figure 2: Energy balace of MED plant coupled to DEAHP

ferred by the solar field, by the DEAHP or by both. When the DEAHP is coupled with the MED plant, the DEAHP evaporator works as $14^{\text {th }}$ effect distillate condenser.

A heat pump is a machine that transfers heat from a low temperature source to a high temperature source. In AQUASOL DEAHP, the low temperature source $\left(35^{\circ} \mathrm{C}\right)$ is the $14^{\text {th }}$ effect cell and the high temperature source is the water that flows from the secondary tank $\left(63.5^{\circ} \mathrm{C}\right)$ to the primary tank $\left(66.5^{\circ} \mathrm{C}\right)$. According to the Second Law of Thermodynamics, an energy input is required to make this heat transfer possible. This energy is provided by steam generated at the gas 


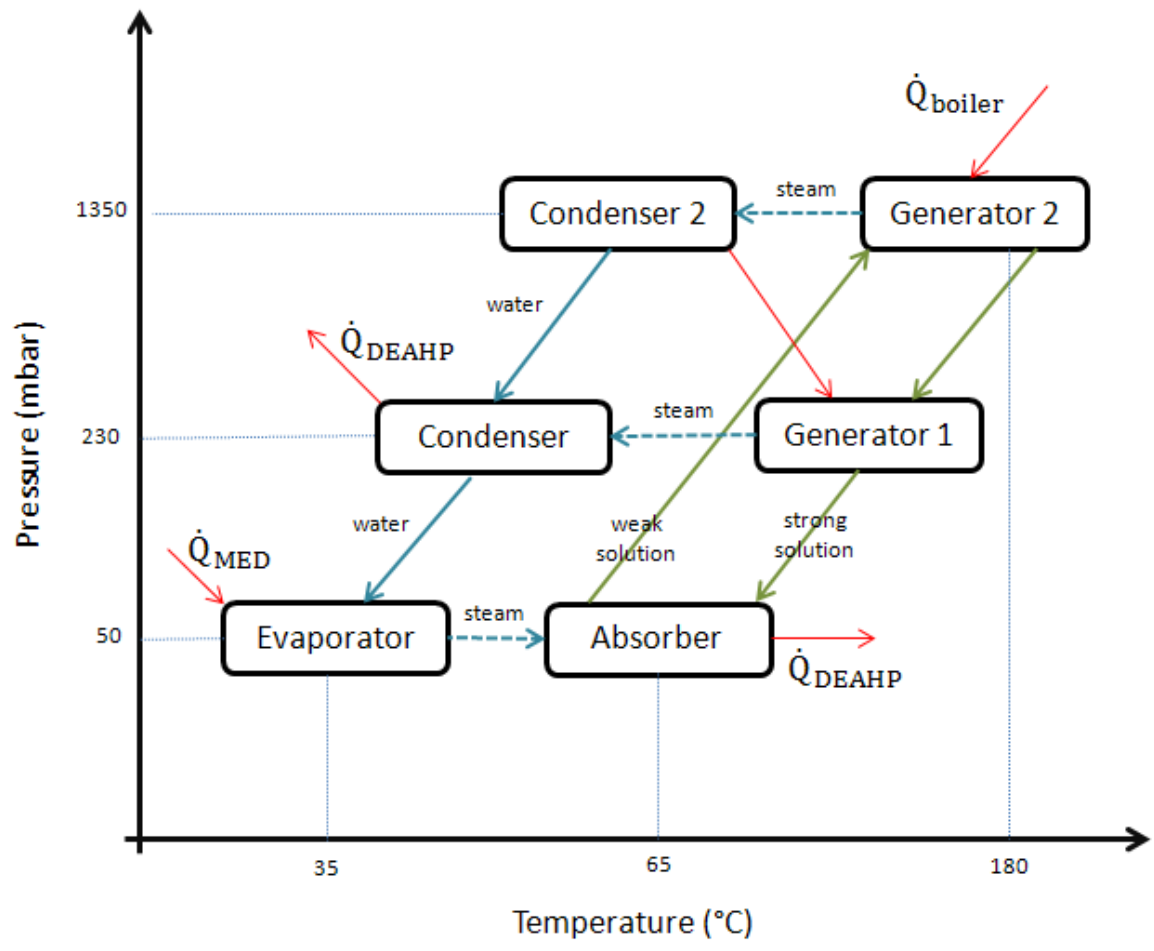

Figure 4: Thermodynamic cycle of the AQUASOL DEAHP

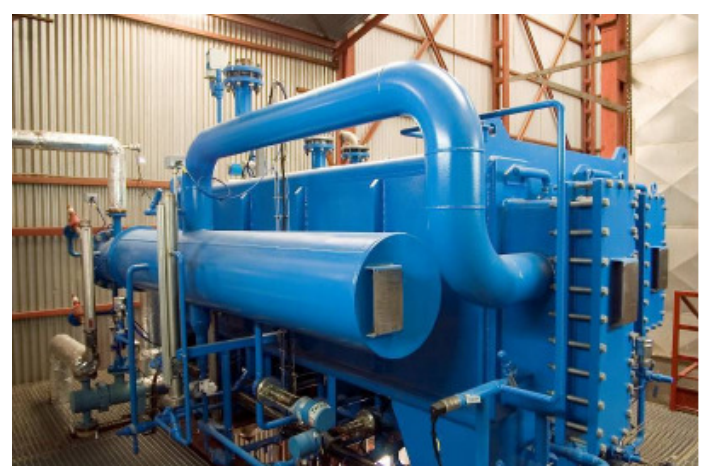

Figure 3: AQUASOL DEAHP, CIEMAT-Plataforma Solar de Almería

boiler $\left(180^{\circ} \mathrm{C}\right)$. Fig. 2 shows the heat transfer process between the MED plant, the DEAHP and the gas boiler [2].

AQUASOL DEAHP ( Fig. 3) is composed of 5 vessels: one evaporator, one absorber, two generators and one condenser. It uses a water/aqueous lithium bromide solution as working fluid in two fluid interconnected circuits.

Fig. 4 shows the thermodynamic cycle of DEAHP. The low temperature source (steam from $14^{\text {th }}$ effect cell) transfers heat to the low pressure evaporator which generates a steam flow. This steam is absorbed by a strong lithium bromide solution, as a consequence it increases its temperature and transfers the heat to the high temperature source (water that flows from secondary to primary tank). To desorb the weak lithium bromide solution there are two generators with two different pressure levels. The gas boiler transfer heat to the generator 1 desorbing part of the water of the solution. The steam generated is condensed in generator 2 transferring heat and desorbing more water. The steam generated in generator 2 is condensed transferring heat to the hot source. Water from condenser and generator 2 returns to the evaporator and the strong lithium bromide solution return to absorber.

A detailed model of the DEAHP evaporator is presented in this paper. This study has been done under the framework of POWER project.

\section{Mathematical model}

The nomenclature used in this section is described in Appendix A. Newton's notation is used for time derivatives.

AQUASOL DEAHP evaporator is a horizontaltubes-falling-film-type evaporator. Falling film evaporators have demonstrated better performance than flooded tubes evaporators in air conditioning and refrigeration applications due to its higher heat transfer 


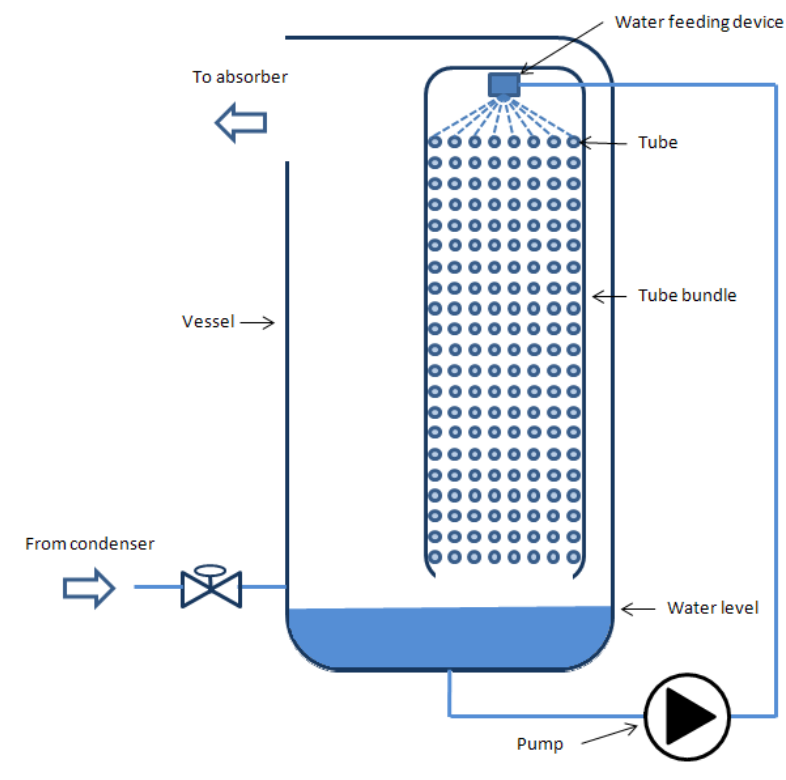

Figure 5: DEAHP evaporator scheme

coefficient and its smaller size [4].

A schematic cross section of the evaporator is shown in Fig. 5. Water is sprayed over the first row of the bundle tube structure. Over the tube surface, a thin film of water is formed. Water in the film flows downward under the gravitational force, falling one by one over all the column tubes. The film thickness determines the mass and heat flow rates.

The water feeding device can affect evaporator performance because it determines the water distribution over the tubes. In the model a uniform water distribution is assumed. When the water film flow rate falls below a certain limit dry patches are formed. This reduces the effective wetted area and consequently the heat transfer. An empirical correlation of the apparent wet area fraction $F=A_{\text {wet }} / A_{t}$ is presented in [5]. The fraction is calculated according to Eq. 1 . If $F$ is equal or less than $1, F$ is fixed to 1 .

$$
F=0.0024 R e_{\text {top }}^{0.91}
$$

This correction is included in the model through the wetted length, $l_{\text {wet }}$, which is estimated with $F$ and the real length $l$.

$$
l_{w e t}=l F
$$

A classical formulation is used to model the dynamics of the falling film displacing over the tubes. It is assumed that the film thickness is constant over the tube as shows Fig. 6. According to it and using Newton's Law of Viscosity the force balance equation for the liquid film can be expressed as:

$$
\mu \frac{d u}{d y}=\sum \tau_{s}=\rho g(\delta-y) \sin (\theta)
$$

Integrating over the spacial coordinates Eq. 3 and applying the boundary condition $u=0$ at $y=\delta$, the velocity profile is:

$$
u=\frac{\rho g}{\mu}\left(\delta y-\frac{y^{2}}{2}\right) \sin (\theta)
$$

The downward average film velocity depending on the angle is:

$$
\bar{u}=\frac{1}{\delta} \int_{0}^{\delta} \frac{\rho g}{\mu}\left(\delta y-\frac{y^{2}}{2}\right) \sin (\theta) d y=\frac{\rho g \delta^{2}}{3 \mu} \sin (\theta)
$$

The average film velocity over the tube is calculated integrating Eq. 5 over half of the tube circumference from the top to the bottom:

$$
v=\frac{1}{\pi} \int_{0}^{\pi} \frac{\rho g \delta^{2}}{3 \mu} \sin (\theta) d \theta=\frac{2 g \rho \delta^{2}}{3 \pi \mu}
$$

The mass flow rate at the bottom of the tube is:

$$
\dot{m}_{b o t}=2 \Gamma l_{w e t}=2 v \delta \rho l_{w e t}=\frac{4 g l_{w e t} \rho^{2} \delta^{2}}{3 \pi \mu}
$$

Eq. 7 has a quadratic relationship with the film thickness.

The film thickness can be calculated using the density definition:

$$
\begin{gathered}
\rho=\frac{m}{V}=\frac{m}{\pi l_{w e t}(r+\delta)^{2}-\pi l_{\text {wet }} r^{2}} \\
\delta=-r+\sqrt{r^{2}+\frac{m}{\pi \rho l_{\text {wet }}}}
\end{gathered}
$$

where $m$, the mass of the water stuck to the outer surface of the tube, is calculated with the mass balance over the tube:

$$
\dot{m}=\dot{m}_{t o p}-\dot{m}_{b o t}-\dot{m}_{e v}
$$

According to Nusselt's classical theory on falling film condensation, heat is transferred by conduction across the falling film. Same assumption is used in this model. Applying Fourier's law:

$$
\dot{Q}_{\text {tube }}=k A_{\text {wet }} \frac{T_{\text {tube }}-T}{\delta}
$$

The thin film energy balance is:

$$
\dot{U}=\dot{Q}_{t u b e}+\dot{m}_{t o p} h_{t o p}-\dot{m}_{b o t} h_{b o t}-\dot{m}_{e v} h_{e v}
$$

where $\dot{Q}_{\text {tube }}$ is the heat flow rate transferred by the tube, $\dot{m}_{b o t}$ is calculated with Eq. $7, h_{b o t}$ is assumed as the falling film specific enthalpy and $h_{e v}$ the specific enthalpy of saturated vapor. 


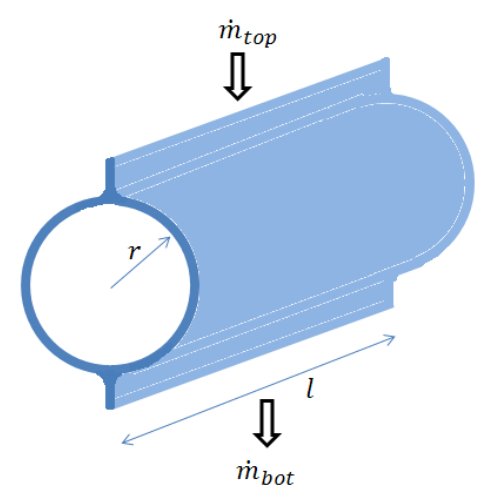

(a) Falling film in sheet mode

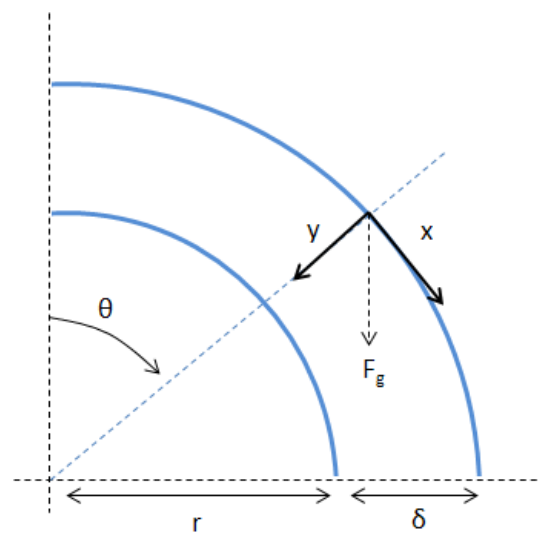

(b) Falling film scheme

Figure 6: Falling film on a horizontal tube

To determine the evaporated mass flow rate, the following relationship is used:

$$
\dot{m}_{e v}=\frac{1}{h_{s g}-h_{s l}}\left(\dot{Q}_{t u b e}-m \dot{h}_{s l}-\dot{m}_{t o p}\left(h_{s l}-h_{t o p}\right)\right)
$$

where the mass of evaporated water is adapted with changes in the pressure and in the inlet mass flow rate.

The pressure inside the evaporator is estimated with the ideal gas law because the evaporator works at low pressures.

\section{Modelica library}

A new library to simulate a falling film evaporator has been developed using Modelica version 3.2. This library is completely compatible with Modelica.Fluid, Modelica.Thermal and Modelica.Media. Water thermodynamic properties have been calculated using the package Modelica.Media.Water.StandardWater.

The library is divided in the tube model, the tube conduction model, the tube column model and the tube bundle model.

The tube model is the basic class which includes all the equations that models the mass and energy balances in one single control volume. As inputs the model has a fluid port of top inlet flow and a heat port connected to the Nusselt falling film conduction model, as outputs it has two fluid ports, one for the outlet flow that falls by gravity at the bottom and one to evacuate the steam generated, and a real output to provide conduction model the heat transfer coefficient. The model obtains the water initial state variables (temperature and pressure) through an outer
Modelica.Fluid.System class. The parameters of the tube model are shown in Fig. 7.

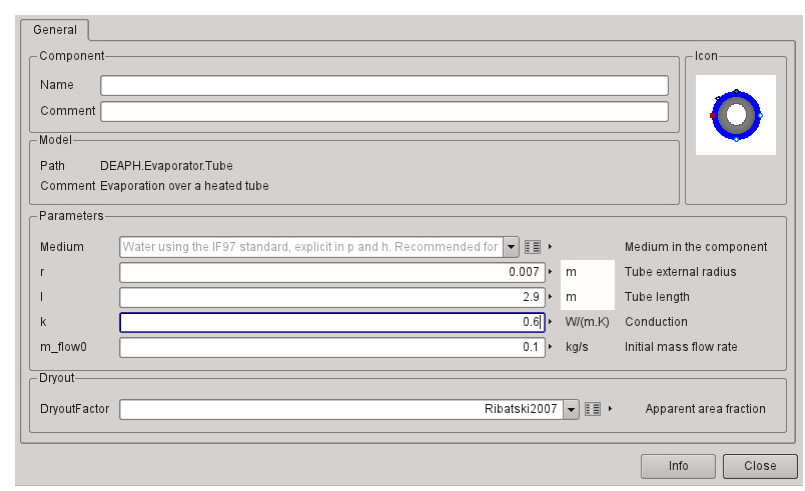

Figure 7: Tube model parameter menu

The tube conduction model joins a conduction model with a tube model, modeling the mass and energy dynamics of the falling film outside the tube. It has three fluid ports (top, bottom and steam) and one heat port where the metal tube transfers heat to the falling film.

The tube column model uses an array of tube conduction models in order to model one of the evaporator columns. The tube conduction models are connected consecutively one by one through top and bottom fluid ports, making a column of tubes. The steam fluid ports are interconnected between them in a single output fluid port. Also, the heat ports are interconnected between them, hence, assuming the same temperature. This assumption is possible because inside the tubes flow steam that is condensated transferring heat but keeping constant the temperature.

The tube bundle model adds to the tube col- 
umn model the dynamics of an evaporator with many columns. This model assumes that all the columns have the same dynamics and extrapolates the results of one single column to all of them. The model additionally includes a conduction model where the conduction across the tubes is modeled as one single mass that transfers heat from the single mass to the outside.

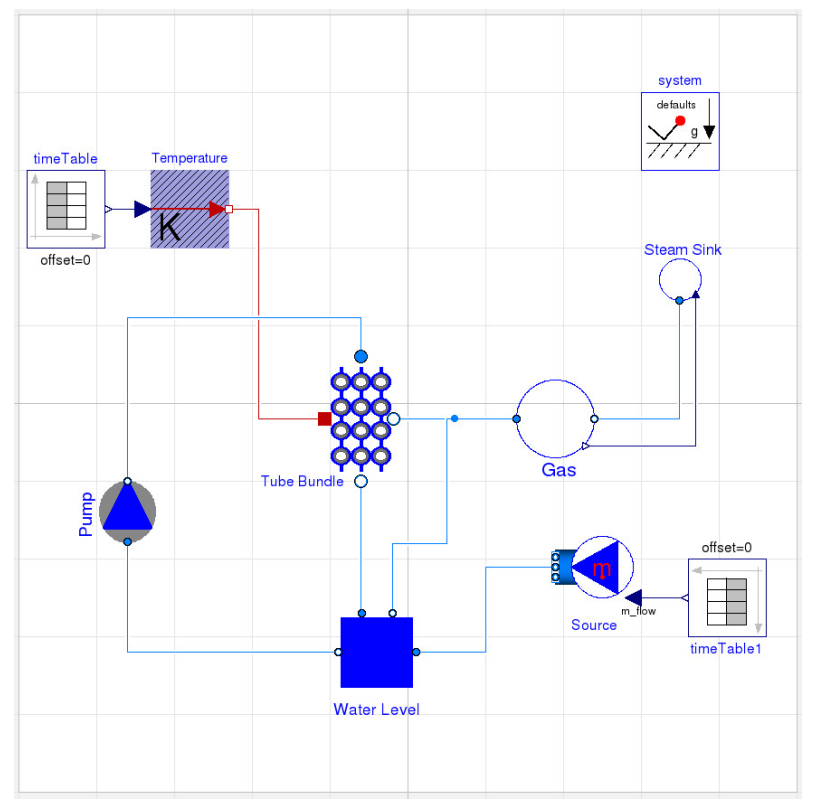

Figure 8: DEAHP evaporator in Modelica

\section{Simulation}

The model used to simulate the evaporator shown in Fig. 5 is composed of a tube bundle model, a water level model, a pump model, a gas model, a steam sink model and a water source model. The water level model simulates the mass and energy balances of the vessel under the tubes. The water in the vessel is recirculated with the help of a pump to the tube bundle as it is shown in Fig. 8. The gas model considers the mass and energy balances of a mixture of gases (steam and air) in the evaporator vessel where the pressure is given with the ideal gas law. The steam sink model is a first approximation to model the absorber where the steam leaves the vessel always with a steam mass flow rate lower than the saturation boundary. Water source model is used to control the vessel water level. The simulated tube bundle has 8 columns and 25 rows.

The simulation time was $25.8 \mathrm{~s}$ of $100 \mathrm{~s}$. It has been performed starting from steady-state initial conditions. When the evaporator is started, an ideal pump flows a constant water flow rate to the tube bundle and each tube in the model has the same inlet flow rate. Water and tubes start at the same temperature. At simulation time $20 \mathrm{~s}$, the tubes progressively raise its temperature until time $40 \mathrm{~s}$ and where its temperature reach steady-state. Water starts evaporating. First, water heats the gas increasing slightly the pressure, and then, the gas leaves the vessel. When the steam sink model reaches its saturation mass flow rate, the pressure inside the vessel raises and that increases also the specific enthalpy of saturated liquid. This pressure rise stops when the evaporated mass flow rate reaches the saturation mass flow rate boundary given by the steam sink model.

Simulation results are shown in Fig. 9. Fig. 9a at the top depicts the total heat flow rate transferred by the tubes to the falling film. At the bottom a comparison between tube wall temperature and inlet and outlet water temperature of the tube bundle is shown. Fig. 9bI shows the variation of the pressure inside the vessel. This variation affects to the specific enthalpy of the saturated liquid as is depicted at Fig. 9bII. Also, in this figure is shown that while the $25^{\text {th }}$ tube row begins to evaporate, at the $1^{\text {st }}$ tube row the specific enthalpy of the inlet water is lower than the specific enthalpy of saturated water until the evaporator heats all the water in the vessel and the water in the vessel reaches the saturated temperature. Evolution of dry patches in tubes can be observed in Fig. 9c. Dryout disappears when water temperature increases and the Reynols number increases too. Besides, in this figure can be observed the evolution of the falling film thickness along the experiment. Fig. 9d shows the steam mass flow rate generated in the evaporator. As it can be seen, the simulation has chattering in some of the tubes when the pressure increases, even though this effect has been foreseen in Eq. 12. Numerical errors taken into account could probably be the origin of this problem.

\section{Conclusions}

A new dynamic model of a falling film evaporator has been developed. The model is framed in a project which studies the AQUASOL DEAHP. A Modelica library for falling films evaporators has been implemented. The library is based on Newton's viscosity law and Nusselt's classical theory of falling film and it is compatible with Modelica.Fluid, Modelica.Thermal and Modelica.Media libraries. The simulations show the expected performance within the range which it has been designed in spite of chattering in evaporation. The chattering problem will be studied in detail in future works and possible solutions like hysteresis 
are going to be tested. The library will be extended with new components that will model absorbers and generators. Models will be calibrated and validated with experimental data and control algorithms will be proposed to optimize the DEAHP performance.

\section{Appendix A. Nomenclature}

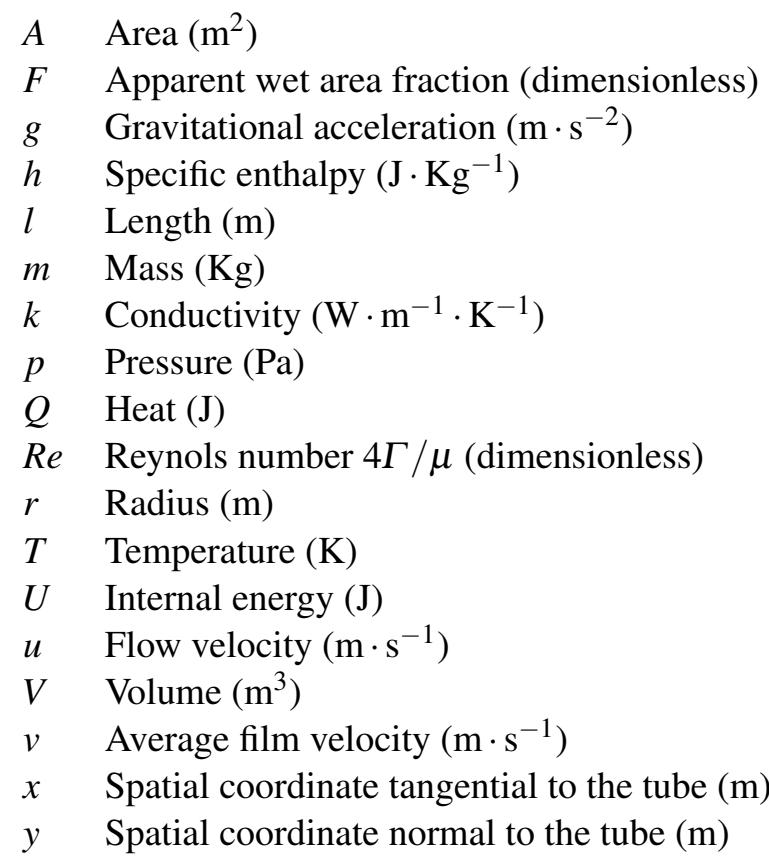

\section{Greek symbols}

$\delta \quad$ Film thickness (m)

$\Gamma \quad$ Liquid mass flow rate per unit length of tube (each side) $\left(\mathrm{Kg} \cdot \mathrm{m}^{-1} \cdot \mathrm{s}^{-1}\right)$

$\theta \quad$ Angle (rad)

$\mu \quad$ Dynamic viscosity $\left(\mathrm{Kg} \cdot \mathrm{m}^{-1} \cdot \mathrm{s}^{-1}\right)$

$\rho$ Density $\left(\mathrm{Kg} \cdot \mathrm{m}^{-3}\right)$

$\tau_{s} \quad$ Shear stresses $(\mathrm{Pa})$

\begin{tabular}{ll}
\multicolumn{2}{l}{ Subscripts } \\
bot & bottom \\
ev & evaporated \\
sg & saturated gas \\
sl & saturated liquid \\
t & total \\
top & top \\
tube & tube \\
wet & wetted
\end{tabular}

\section{Acknowledgements}

The authors would like to thank to CIEMAT reseach centre, Spanish Ministry of Economy and Competitiveness and FEDER funds for financed this work un- der the National Plan Project, Predictive control techniques for efficient management of renewable energy microgrids. (POWER), DPI2010-21589-C05-02 and the INNPACTO project, Hibridación de tecnologías renovables en una planta de generación de energía. (HIBIOSOLEO), IPT-440000-2010-004.

\section{References}

[1] D. C. Alarcón-Padilla, J. Blanco-Gálvez, L. García-Rodríguez, W. Gernjak, and S. Malato. First experimental results of a new hybrid solar/gas multi-effect distillation system: the AQUASOL project. Desalination, 220(1-3):619625, 2008.

[2] D. C. Alarcón-Padilla, L. García-Rodríguez, and J. Blanco-Gálvez. Assessment of an absorption heat pump coupled to a multi-effect distillation unit within AQUASOL project. Desalination, 212(1-3):303-310, 2007.

[3] D. C. Alarcón-Padilla, L. García-Rodríguez, and J. Blanco-Gálvez. Experimental assessment of connection of an absorption heat pump to a multieffect distillation unit. Desalination, 250(2):500505, 2010.

[4] G. Ribatski and A. M. Jacobi. Falling-film evaporation on horizontal tubes-a critical review. International Journal of Refrigeration, 28(5):635653, 2005.

[5] G. Ribatski and J. R. Thome. Experimental study on the onset of local dryout in an evaporating falling film on horizontal plain tubes. Experimental Thermal and Fluid Science, 31(6):483-493, 2007.

[6] E. Zarza, J. Ajona, J. León, A. Gregorzewski, and K. Genthner. Solar thermal desalination project at the Plataforma Solar de Almeria. Solar Energy Materials, 24(1-4):608-622, 1991. 
(I)

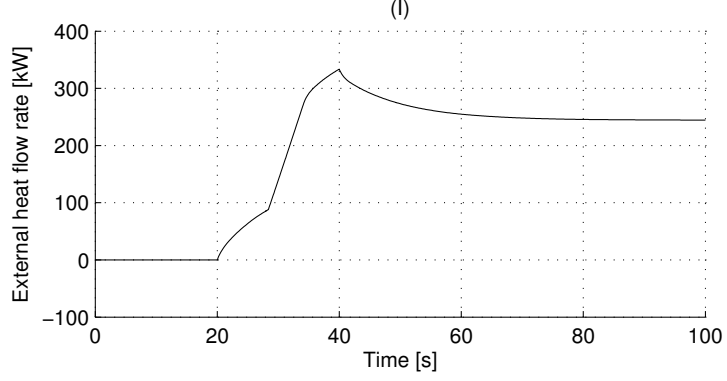

(II)

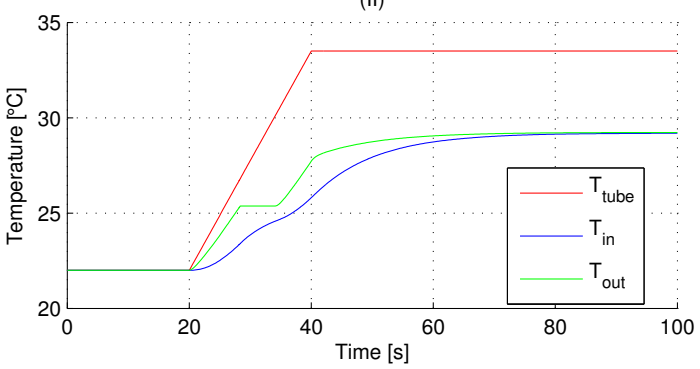

(a) (I) Inlet heat flow rate across tubes (II) Tube wall temperature, (b) (I) Pressure in the evaporator (II) Specific enthalpy of satinlet water temperature, outlet water temperature

(I)

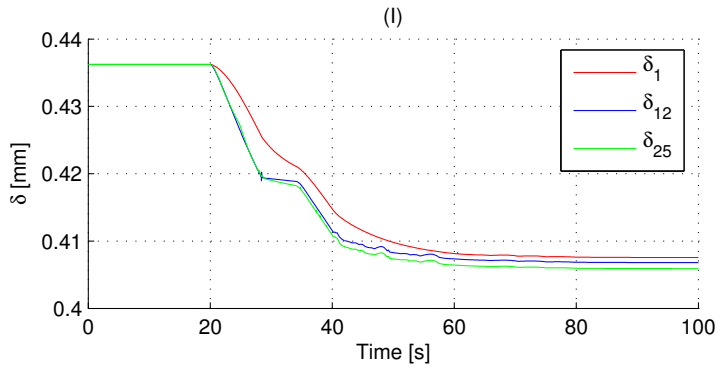

(II)

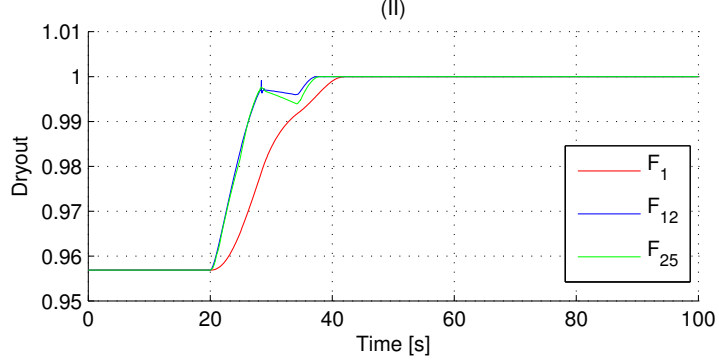

(I)

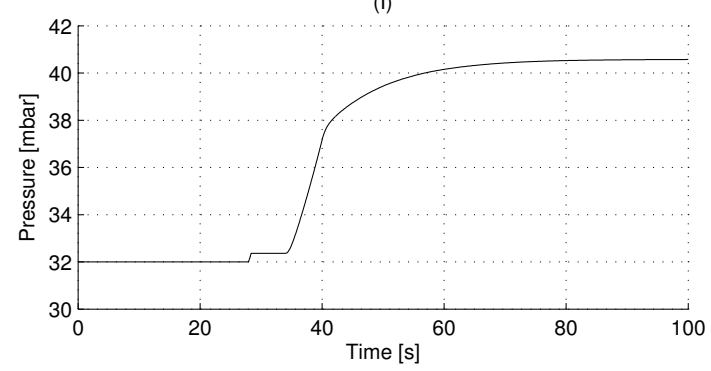

(II)

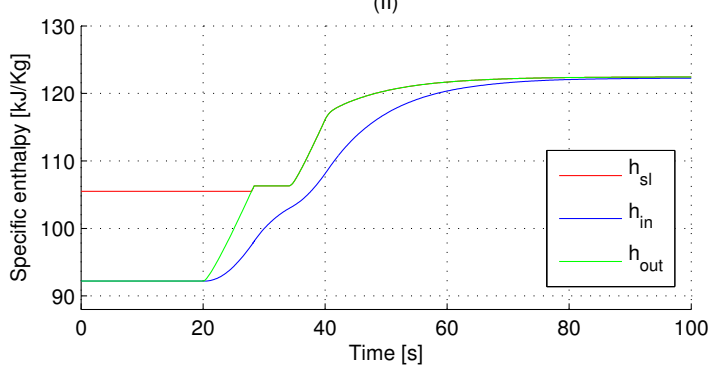
urated liquid, inlet water specific enthalpy, outlet water specific enthalpy

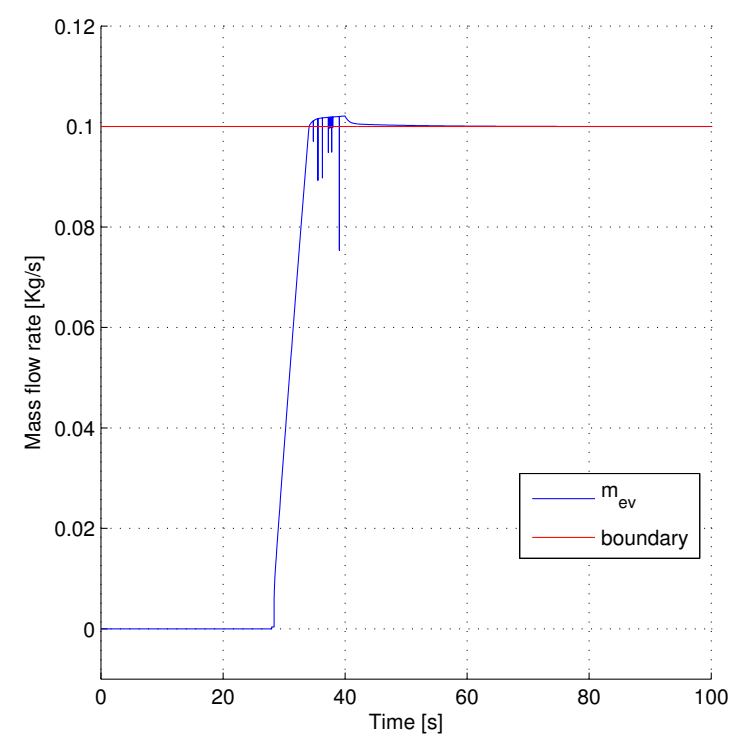

(c) (I) Falling film thickness in tube 1, 12 and 25 (II) Apparent (d) Evaporated water mass flow rate and sink saturation boundary wet area fraction

Figure 9: Simulation results 
